\title{
Study of $\mathrm{VD}_{3}-\beta$-Clodextrin Inclusion Complex
}

\author{
Yan Liu1, Huayang Zhang2* \\ ${ }^{1}$ School of Chinese Materia Medica, Tianjin University of Traditional Chinese Medicine, Tianjin, China \\ ${ }^{2}$ Oncological Surgery, Tianjin Nankai Hospital, Tianjin, China \\ Email: "lytjsy@163.com
}

Received 13 March 2016; accepted 25 April 2016; published 28 April 2016

Copyright (C) 2016 by authors and Scientific Research Publishing Inc.

This work is licensed under the Creative Commons Attribution International License (CC BY).

http://creativecommons.org/licenses/by/4.0/

cc) (7) Open Access

\begin{abstract}
Vitamin D is responsible for enhancing intestinal absorption of calcium, iron, magnesium, phosphate and zinc by involving in the metabolism. However, its use in additive field is limited by its low aqueous solubility and chemical stability. So trace amounts of $\mathrm{VD}_{3}$ was wrapped in $\beta$-CD molecule by the method of saturated aqueous vacuum drying, in order to improve its stability, uniformity and solubility in food and feed additive. The inclusion complex was characterized by NMR, IR techniques and compared with original $\mathrm{VD}_{3}$ in the aspect of stability and bioavailability. Results of orthogonal design experiments show that the optimum technology of inclusion is that the feed ratio of $\beta$-CD to $\mathrm{VD}_{3}$ is $15: 1$, being stirred for 5 hours at $80^{\circ} \mathrm{C}$. Dispersion of $\mathrm{VD}_{3}$ in the inclusion complex is more uniform, while stability and absorption rate of inclusion complex are significantly higher than original $\mathrm{VD}_{3}$.
\end{abstract}

\section{Keywords}

$\mathrm{VD}_{3}, \beta$-Clodextrin, Inclusion Complex, NMR, IR, Quality Evaluation

\section{Introduction}

Vitamin $\mathrm{D}$, also known as cholecalciferol, including vitamin $\mathrm{D}_{2}$ (ergocalciferol,) and vitamin $\mathrm{D}_{3}$ (cholecalciferol), whose chemical name is 9,10-open-loop cholesteric 5,7,10(19-) leukotriene-3 $\beta$-alcohol, and vasoactive substance is 25 -hydroxy vitamin $\mathrm{D}_{3}$-abbreviated [25-(OH)- $\mathrm{D}_{3}$ ] (calcifediol, INN). In recent years, the demand for $\mathrm{VD}_{3}$ is on the rise, which is widely used in areas of food additives, pharmaceutical preparations and feed additives. Vitamin $\mathrm{D}$ is responsible for enhancing intestinal absorption of calcium, iron, magnesium, phosphate and zinc by involving in the metabolism. In the liver, vitamin $\mathrm{D}_{3}$ is converted to calcifediol, while vitamin $\mathrm{D}_{2}$ is converted to 25-hydroxy vitamin $\mathrm{D}_{2}\left[25-(\mathrm{OH})-\mathrm{D}_{2}\right]$. These two specific vitamin $\mathrm{D}$ metabolites are measured in serum to determine personal vitamin D status. Part of the calcifediol is converted by the kidneys to calcitriol, the

${ }^{*}$ Corresponding author. 
biologically active form of vitamin D. Calcitriol circulates as a hormone in the blood, regulating the concentration of calcium and phosphate in the bloodstream and promoting the healthy growth and remodeling of bone. Calcitriol also affects neuromuscular and immune function [1]-[3]. Therefore vitamin D has gradually become an important auxiliary material in food industry. But because of its very small added amount, whether it can be uniformly dispersed in the raw material becomes extremely important. Since the vitamin D molecule has many Olefinic bonds, it is unstable and easy to be oxidized in humid environment [4] [5]. In the aspect of increasing the solubility, reducing volatility, enhancing chemical stability of food additive, extending food shelf life and stabilizing food color, $\beta$-CD is widespread used [6]. In this study, $\mathrm{VD}_{3}-\beta$-cyclodextrin inclusion complex is prepared by saturated aqueous vacuum drying method, in order to improve its stability and uniformity in food and feed additive [7].

\section{Experimental}

\subsection{Materials and Animals}

Original $\mathrm{VD}_{3}$; $\beta$-CD; acetonitrile; 25-hydroxy vitamin $\mathrm{D}_{3}$ ELISA kit; ether. Wistar rats (male, weighing $200 \pm$ $20 \mathrm{~g})$.

\subsection{Preparation of the Standard Solution and Test Solution}

$\mathrm{VD}_{3}$ standard were precisely Weighed $10.05 \mathrm{mg}$, placed into $50 \mathrm{ml}$ measuring flask, and dissolved by methanol to make the stock solution whose $\mathrm{VD}_{3}$ concentration was $201.0 \mu \mathrm{g} / \mathrm{ml}$. Then the stock solution was shaken well and precisely taken $2 \mathrm{ml}$ to a $10 \mathrm{ml}$ volumetric flask, Which Methanol was added to in order to make the standard solution whose $\mathrm{VD}_{3}$ concentration was $40.20 \mu \mathrm{g} / \mathrm{ml}$. The determinand was precisely Weighed $80 \mathrm{mg}$ to 10 $\mathrm{ml}$ measuring flask, and completely wetted up by adding $5 \mathrm{ml}$ dimethyl sulfoxide. Then the particles were ultrasound dissolved. Methanol was added to dilute the solution to the mark. Then the solution was filtered through $0.45 \mu \mathrm{m}$ organic microporous membrane. The filtrate was the test solution.

\subsection{Inclusion Orthogonal Design}

By pre-experiment study, the main factors of influencing the effect of inclusion by saturated aqueous solution vacuum drying method were the original feed ratio of $\beta$-CD and $\mathrm{VD}_{3}$, the stirring temperature and stirring time. So L9 $\left(3^{4}\right)$ orthogonal design was used and the inclusion rate was the evaluation index to choose the optimum process (Tables 1-3). Among them, the inclusion rate $=$ amount of drug in inclusion compound/total dosage $\times$ $100 \%$.

\subsection{Preparation of Samples}

\subsubsection{Preparation of the $\mathrm{VD}_{3}-\beta$-CD Inclusion Complex}

$B$-CD was weighed $15 \mathrm{~g}$, and was suspended in $150 \mathrm{ml}$ distilled water, heated to $60^{\circ} \mathrm{C}$, to make saturated aqueous solution of $\beta$-CD; $\mathrm{VD}_{3}$ was weighed $1.0 \mathrm{~g}$ and dissolved in $5 \mathrm{ml}$ distilled water. The original $\mathrm{VD}_{3}$ aqueous solution was added dropwise to the $\beta$-CD aqueous solution, stirred for $5 \mathrm{~h}\left(80^{\circ} \mathrm{C}, 600 \mathrm{r} / \mathrm{min}\right)$, then frozed for $24 \mathrm{~h}$ at $4^{\circ} \mathrm{C}$, vacuum filtered. The filter cake was dried in an electrothermal vacuum oven at room temperature. The $\mathrm{VD}_{3}-\beta$-cyclodextrin inclusion complex was obtained by smashing the dried filter cake, weighed, and sifted through the 100 mesh sieve to be reserved [8]-[10].

\subsubsection{Preparation of the Physical Mixture}

The calculated and exactly weighed (1:1 molar ratio) amounts of $\mathrm{VD}_{3}$ and $\beta$-CD were pulverized in a ceramic

Table 1. $\mathrm{L}_{9}\left(3^{4}\right)$ factors-levels of the inclusion process.

\begin{tabular}{cccc}
\hline Level & $\mathrm{A}\left(\beta-\mathrm{CD} / \mathrm{VD}_{3}\right)$ & $\mathrm{B}$ (stirring temperature) & $\mathrm{C}(\mathrm{stirring}$ time) \\
1 & $5: 1$ & $40^{\circ} \mathrm{C}$ & $3 \mathrm{~h}$ \\
2 & $10: 1$ & $60^{\circ} \mathrm{C}$ & $5 \mathrm{~h}$ \\
\hline
\end{tabular}


Table 2. $\mathrm{L}_{9}\left(3^{4}\right)$ orthogonal experimental results.

\begin{tabular}{cccccc}
\hline Test number & A & B & C & D & Inclusion rate \\
\hline 1 & 1 & 1 & 1 & 1 & 0.3068 \\
2 & 1 & 2 & 2 & 2 & 0.1258 \\
3 & 1 & 3 & 3 & 3 & 0.4036 \\
4 & 2 & 1 & 3 & 3 & 0.1955 \\
5 & 2 & 2 & 1 & 1 & 0.2012 \\
6 & 2 & 3 & 2 & 0.2884 \\
7 & 3 & 1 & 2 & 0.3093 \\
8 & 3 & 2 & 3 & 3 & 0.5114 \\
9 & 3 & 3 & 1 & 1 & 0.2825 \\
$\mathrm{k}_{1}$ & 0.84 & 0.81 & 0.79 & 0.79 & 0.72 \\
$\mathrm{k}_{2}$ & 0.69 & 0.84 & 0.72 & 1.11 & 0.13 \\
$\mathrm{k}_{3}$ & 1.10 & 0.97 & 1.11 & 0.029 \\
Range & 0.14 & 0.05 & 0.17 & 0.043 & \\
SSj & 0.03 & 0.005 & & 2 & \\
\hline
\end{tabular}

Table 3. Variance analysis.

\begin{tabular}{ccccccc}
\hline Source of variation & SS & DOF & Variance & F value & Critical value & Significance \\
\hline 1 & 0.030 & 2 & 0.015 & 23.905 & 4.459 & $*$ \\
2 & 0.005 & 2 & 0.003 & 4.069 & & $*$ \\
3 & 0.043 & 2 & 0.021 & 34.324 & 22.814 & $*$ \\
4 & 0.029 & 2 & 0.014 & & \\
Overall error & 0.005 & 8 & 0.001 & & \\
\hline
\end{tabular}

Notes: ${ }^{*} \mathrm{P}<0.05$.

mortar and carefully mixed.

\subsection{Quality Assessment of theVD ${ }_{3}-\beta$-CD Inclusion Complex}

$\mathrm{VD}_{3}, \beta$-CD, the $\mathrm{VD}_{3}-\beta$-CD inclusion complex made by the best technology and the physical mixture were weighed $10 \mathrm{mg}$ each calculated by the inclusion rate. IR spectra were performed under the same conditions to verify whether the inclusion complex was formed by comparing infrared absorption peak.

Stability constants were measured by the method of thermostatic acceleration. $\mathrm{VD}_{3}$ test sample and inclusion complex were put in thermostatic water bath $\left(25^{\circ} \mathrm{C}\right)$. Samples of $2 \mathrm{ml}$ were taken at $60,120,180,240,300$ minute, and filtered through $0.45 \mu \mathrm{m}$ microporous membrane. Finally, the filtrate was measured to record peak area.

30 male Wistar rats were randomly divided into two groups, and intragastric administrated pure $\mathrm{VD}_{3}$ and $\mathrm{VD}_{3}$ inclusion complex according to $4.5 \mu \mathrm{g} \mathrm{VD}_{3}$ per kilogram body weight. Concentration of 25 -hydroxy $\mathrm{VD}_{3}$ in serum was measured by euzymelinked immunosorbent assay (ELISA). The pharmacokinetic parameters of 25hydroxy $\mathrm{VD}_{3}$ in Wistar rats' serum were calculated by PKSolver 2.0 pharmacokinetics software.

\section{Results and Discussion}

\subsection{IR Spectrum}

The IR spectroscopic analysis confirmed the interaction and the complex formation between $\mathrm{VD}_{3}$ and $\beta$-CD. IR 
spectra of the complex were compared with the physical mixture and pure substances. It can be seen that the stretching vibration peak of $\mathrm{O}-\mathrm{H}$ in $\beta$-CD inclusion complex moves significantly to the high band compared with that in $\beta$-CD (change value was $12 \mathrm{~cm}^{-1}$ ). And the stretching vibration peak of $\mathrm{O}-\mathrm{H}$ in $\beta$-CD inclusion complex becomes stronger and narrower, which shows that association effect between $\mathrm{O}$ and $\mathrm{H}$ in $\beta$-CD molecule is weakened by $\mathrm{VD}_{3}$ intervention, confirming the existence of the inclusion complex (see Figure 1).

\subsection{Comparison of Stability}

Concentration of $\mathrm{VD}_{3}$ at each test time point was calculated by standard curve method. At certain temperature, a graph of logarithm of $\mathrm{VD}_{3}$ concentration $(\log \mathrm{C}$ ) versus time $(\mathrm{t})$ is plotted and fitted, whose slope is $\mathrm{m}$, and the degradation rate constant $(\mathrm{K})$ is equal to $-2.303 \mathrm{~m}$. Graph of logarithm of degradation rate constant $(\log \mathrm{K}, \mathrm{K}=$ $-2.303 \mathrm{~m}$ ) versus reciprocal of corresponding absolute temperature $(1 / \mathrm{T})$ is a fitted straight line. Results of degradation rate constant at the room temperature $\left(\mathrm{K}_{25}\right)$ is showed in Table 4, showing the inclusion complex is significantly higher stable than original $\mathrm{VD}_{3}$.

\subsection{Relative Bioavailability}

Elimination rate constant $(k)$, the half-life period $\left(t_{1 / 2}\right)$, time of maximum concentration $\left(T_{\max }\right)$ and mean residence time (MRT) of $\mathrm{VD}_{3}-\beta$-CD inclusion complex are similar to those of original $\mathrm{VD}_{3}$, but $\mathrm{C}_{\max }, \mathrm{AUC}_{0-\infty}$ are obviously larger. According to the formula: $\mathrm{F}=\mathrm{AUC}_{0-\mathrm{t}}(\mathrm{TF}-\mathrm{NE}) / \mathrm{AUC}_{0-\mathrm{t}}(\mathrm{TF}) \times 100 \%$, the relative bioavailability of $\mathrm{VD}_{3}-\beta$-CD inclusion complex to original $\mathrm{VD}_{3}$ is calculated, and the result is $209 \%$. Through process improvement, dispersion of $\mathrm{VD}_{3}-\beta$-CD inclusion complex is more uniform, and absorption rate is significantly higher than original $\mathrm{VD}_{3}$ (see Table 5).

\section{Conclusions}

Because of its very small amount in food additive, the inclusion complex is easy to be mixed unevenly, which
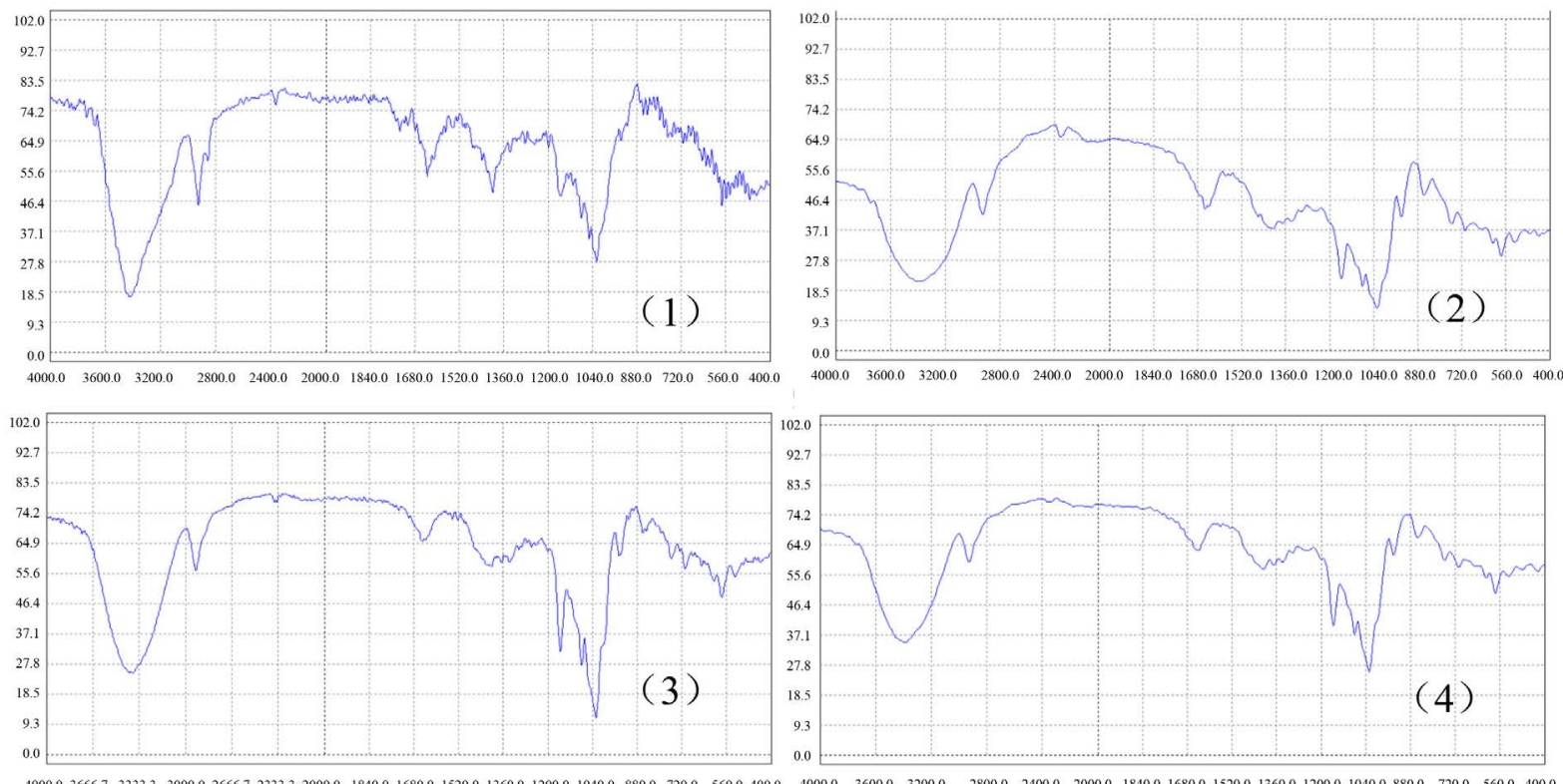

Figure 1. IR spectra: (1) $\mathrm{VD}_{3}$; (2) $\beta$-CD; (3) $\mathrm{VD}_{3}-\beta$-CD inclusion complex; (4) equimolecular physical mixture of $\mathrm{VD}_{3}$ and $\beta$-CD.

Table 4. Degradation rate constant and half-life period of original $\mathrm{VD}_{3}$ and the inclusion.

\begin{tabular}{ccccccc}
\hline & $\mathrm{m}$ & $\mathrm{K}$ & $\operatorname{logK}$ & $1 / \mathrm{T}$ & $\mathrm{t}_{1 / 2}(\mathrm{~h})$ & $\mathrm{t}_{0.9}(\mathrm{~h})$ \\
\hline original $\mathrm{VD}_{3}$ & $-1.06 \times 10^{-2}$ & $2.44 \times 10^{-2}$ & -1.613 & $3.4 \times 10^{-3}$ & 28.40 \\
Inclusion complex & $-2.0 \times 10^{-4}$ & $4.61 \times 10^{-4}$ & -3.336 & $3.4 \times 10^{-3}$ & 1503.25 \\
\hline
\end{tabular}


Table 5. The pharmacokinetic parameters of 25-hydroxy $\mathrm{VD}_{3}$ in Wistar rats’ serum.

\begin{tabular}{cccc}
\hline pharmacokinetic parameters & Unit & $\mathrm{VD}_{3}-\beta$-CD inclusion complex & $\mathrm{VD}_{3}$ \\
\hline $\mathrm{K}$ & $\mathrm{min}^{-1}$ & $7.04 \times 10^{-4}$ & $8.96 \times 10^{-4}$ \\
$\mathrm{t}_{1 / 2}$ & $\mathrm{~min}$ & 985 & 774 \\
$\mathrm{~T}_{\max }$ & $\min$ & 2 & 5 \\
$\mathrm{C}_{\max }$ & $\mu \mathrm{g} / \mathrm{L}$ & 24.09 & 13.84 \\
$\mathrm{AUC}_{0-\infty}$ & $\mu \mathrm{g} / \mathrm{L} \cdot \min$ & $1.81 \times 10^{4}$ & $7.38 \times 10^{3}$ \\
$\mathrm{AUC}_{0-\mathrm{t}}$ & $\mu \mathrm{g} / \mathrm{L} \cdot \min$ & $7.88 \times 10^{3}$ & $3.77 \times 10^{3}$ \\
$\mathrm{MRT}$ & $\min$ & $1.72 \times 10^{3}$ & $1.62 \times 10^{3}$ \\
\hline
\end{tabular}

can even lead poisoning [11]. In this study, trace amounts of $\mathrm{VD}_{3}$ were wrapped in $\beta$-CD molecule by the method of saturated aqueous vacuum drying, in order to improve its stability, uniformity and solubility in food and feed additive. While rats' blood pharmacokinetic study indicates that the bioavailability of $\mathrm{VD}_{3}-\beta$-CD inclusion complex is also better. The experiments show that the optimum technology of inclusion is that the feed ratio of $\beta$-CD to $\mathrm{VD}_{3}$ is $15: 1$, being stirred for 5 hours at $80^{\circ} \mathrm{C}$, which can be widely used in additive to improve safety, effectiveness, and economy.

\section{Funding}

Fund project (No. 14TXZYJC00440), named science and technology achievements transformation center construction of Tianjin University of Traditional Chinese Medicine.

\section{References}

[1] Haynes, D.R., Athkins, G.J. and Loric, M. (1999) Bidirectional Signaling between Stromal and Hemopoietic Cells Regulates Interleukin-1 Expression during Human Osteoclast Formation. Bone, 25, 269-278. http://dx.doi.org/10.1016/S8756-3282(99)00176-3

[2] Suda, T. (2002) How Is Bone Formed and Resorbed?-Molecular Mechanisms of Bone Formation and Resorption. Japanese Journal of Clinical Pathology, 50, 267-272.

[3] Haddad, J.G., Matsuoka, L.Y., Hollis, B.W., Hu, Y.Z. and Wortsman, J. (1993) Human Plasma Transport of Vitamin D after Its Endogenous Synthesis. Journal of Clinical Investigation, 91, 2552-2555. http://dx.doi.org/10.1172/JCI116492

[4] Heike, A., Bischoff-Ferrari, M.D. and MPH Walter, C. (2005) Fracture Prevention with Vitamin D Supplementation. The Journal of the American Medic, 293, 2257-2264. http://dx.doi.org/10.1001/jama.293.18.2257

[5] Grady, L.T. and Thakker, K.D. (1980) Stability of Solid Drugs: Degradation of Ergocalciferol (Vitamin $\mathrm{D}_{2}$ ) and Cholecalciferol (Vitamin $\mathrm{D}_{3}$ ) at High Humidity and Elevated Temperatures. Journal of Pharmaceutical Sciences, 69, 1099-1101. http://dx.doi.org/10.1002/jps.2600690932

[6] Astray, G., Gonzalez-Barreiro, C., Mejuto, J.C., Rial-Otero, R. and Simal-Gándara, J. (2009) A Review on the Use of Cyclodextrins in Foods. Food Hydrocolloids, 23, 1631-1640. http://dx.doi.org/10.1016/j.foodhyd.2009.01.001

[7] Szejtli, J., Bolla-Pusztai, E., Szabo, P. and Ferenczy, T. (1980) Enhancement of Stability and Biological Effect of Cholecalciferol by $\beta$-Cyclodextrin Complexation. Pharmazie, 35, 779-787.

[8] Dong, Z.M., Liu, X.P., Zhang, G.M., et al. (2003) Study on Vitamin $\mathrm{K}_{3}$-Cyclodextrin Inclusion Complex and Analytical Application. Spectrochimica Acta Part A: Molecular and Biomolecular Spectroscopy, 59, 2073-2079. http://dx.doi.org/10.1016/S1386-1425(03)00006-4

[9] Hu, X.T., Wei, B.X., Li, H.Y., et al. (2012) Preparation of the $\beta$-Cyclodextrin-Vitamin C ( $\beta$-CD-Vc) Inclusion Complex under High Hydrostatic Pressure (HHP). Carbohydrate Polymers, 90, 1193-1196. http://dx.doi.org/10.1016/j.carbpol.2012.06.029

[10] Zhang, X.N., Tao, L., Wang, X.L. and Miao, A.D. (2000) Preparation and Characterization of VD $\mathrm{VD}_{3}-\mathrm{CD}_{\text {Inclusion }}$ Complex. Journal of Xinjiang Medical University, 23, 104-107. (In Chinese)

[11] Ma, S.Z. and Zhang, G.C. (2007) Clinical Analysis of $\mathrm{VD}_{3}$ Poisoning for Infants. Heilongjiang Medicine Journal, 20, 177. (In Chinese) 